cis- and trans-diol, together with indan-2-one (Loon, 1919). So far, however, there is no experimental evidence to show that epoxide formation occurs in the animal body during the metabolism of indene.

\section{SUMMARY}

1. Indene has been administered to rabbits by stomach tube, and fractionation of ether extracts of the urine has yielded optically active cis-and trans-indane-1:2-diol in a total amount corresponding to about $5 \%$ of the dose. Acid treatment of the urine, either before or after ether extraction, yielded indan-2-one in amounts corresponding to about $25 \%$ of the dose of indene.

2. The same two diols have been isolated from the urine of rabbits dosed with indene by subcutaneous injection.

3. cis-Indane-1:2-diol has been isolated from ether extracts of the urine of rats dosed with indene by stomach tube. Indan-2-one has been obtained by acid treatment of the extracted urine.

4. The interconversion of cis-and trans-indane1:2-diol has been studied, and the metabolic formation of the two diols is discussed.

The authors gratefully acknowledge the support this work has received from the Endowment Fund of St Thomas's Hospital. The elementary microanalyses were carried out by Weiler and Strauss, Oxford.

\section{REFERENCES}

Böhm, F. (1941). Hoppe-Seyl. Z. 269, 17.

Booth, J. \& Boyland, E. (1949). Biochem. J. 44, 361.

Boyland, E. (1950). Symp. biochem. Soc. no. 5, 40.

Boyland, E. \& Levi, A. A. (1935). Biochem. J. 29, 2679.

Boyland, E. \& Wolf, G. (1948). Biochem. J. 42, xxxii.

Buchanan, J. G., Dekker, C. A. \& Long, A. G. (1950). J. chem. Soc. p. 3162.

Bush, I. E. (1955). Biochem. J. 59, xiv.

Cameron, G. R. \& Doniger, C. R. (1939). J. Path. Bact. 49, 529.

Cook, J. W. (1950). J. chem. Soc. p. 1210.

Corner, E. D. S. \& Young, L. (1954). Biochem. J. 58, 647.

Corner, E. D. S. \& Young, L. (1955). Biochem. J. 61, 132.

Criegee, R., Kraft, L. \& Rank, B. (1933). Liebigs Ann. 507, 159.

Dox, A. W. (1923). Chem. Abstr. 17, 1956.

Hermans, P. H. (1924). Ber. dtsch. chem. Ges. 57, 824.

Ingersoll, A. W. (1944). Org. React. 2, 376.

Loon, C. van (1919). Doctoral Thesis: Technische Hoogeschool, Delft.

Porter, H. D. \& Suter, C. M. (1935). J. Amer. chem. Soc. 57, 2023.

Smith, H. P. \& Whipple, G. H. (1930). J. biol. Chem. 89, 719.

Suter, C. M. \& Milne, H. B. (1940). J. Amer. chem. Soc. 62, 3473.

Whitmore, W. F. \& Gebhart, A. I. (1942). J. Amer. chem. Soc. 64, 912.

Young, L. (1947). Biochem. J. 41, 417.

\title{
Studies of Sebum
}

\section{THE DETERMINATION OF THE COMPONENT FATTY ACIDS OF HUMAN FOREARM SEBUM BY GAS-LIQUID CHROMATOGRAPHY*}

\author{
By A. T. JAMES \\ National Institute for Medical Research, Mill Hill, London, N.W. 7 \\ AND V. R. WHEATLEY \\ Departments of Biochemistry and Dermatology, Medical College of St Bartholomew's Hospital, \\ London, E.C. 1
}

(Received 21 November 1955)

Relatively little information is available concerning the component fatty acids of human sebum. Engman \& Kooyman (1934) made a brief study, using lead-salt separation and fractionation of the bromine derivatives of the liquid acids. They concluded that the free and combined fatty acid fractions of sebum contained both oleic and linoleic acids and that the combined acid fraction also

* Part 5: Wheatley (1954). contained arachidonic acid. They also demonstrated appreciable amounts of saturated products in the liquid acid fraction and concluded that branched-chain acids were possibly present. Ricketts, Squire \& Topley (1951) examined the free fatty acids of human forearm sebum and were able to isolate pure barium oleate (identified by X-ray diffraction). They also reported a chromatographic examination of the saturated fatty acids performed for them by Dr G. A. Howard. This showed the 
presence of at least seven components, of which the most abundant was probably palmitic acid.

Weitkamp, Smiljanic \& Rothman (1947) made a comprehensive study of the free fatty acids of human-hair lipid. They fractionated by amplified distillation the free fatty acids obtained from the lipids from $45 \mathrm{~kg}$. of hair. The source of hair was barber's shop sweepings, and contamination of sebum was likely; nevertheless, they were able to show that the extracted fatty acids constituted a homologous series from $\mathrm{C}_{7}$ to $\mathrm{C}_{22}$, which included both odd and even members. Both saturated and unsaturated acids were present, and the position of the double bonds in the latter was atypical since octadec-6-, -8- and -9-enoic acids were present, whereas the $\mathrm{C}_{16}$ unsaturated acid was hexadec-6enoic acid and not palmitoleic acid. This unusual character of the acids was thought to preclude the possibility of extensive contamination of the hair lipids; nevertheless, it was essential that this work should be repeated on specimens of sebum obtained as free as possible from contamination. Furthermore, it has been observed by Burtenshaw (1942) and by Ricketts et al. (1951) that the selfsterilizing power of human sebum appears to depend on the long-chain unsaturated fatty acids; Rothman, Smiljanic, Shapiro \& Weitkamp (1947) showed that sebum possessed fungicidal properties associated with the shorter-chain saturated acids. It was, therefore, necessary to be able to determine the component fatty acids in a sample of sebum from a single subject in order to make possible the study of the role played by these acids in maintaining the health of the skin.

In view of the complex nature of the fatty acids of human sebum indicated by the work of Weitkamp et al. (1947) the method of choice must have a very high resolving power. Furthermore, sebum from certain animals, e.g. the sheep, contains a high proportion of branched-chain fatty acids, and it is therefore necessary for the method to be able to distinguish between straight- and branched-chain and saturated and unsaturated acids of a homologous series, each member differing by only one carbon atom. Conventional partition-chromatographic methods applied to the separation of fatty acids will usually separate acids which differ in chain length by two carbon atoms, but are useless if applied to sebum analysis. The method of gasliquid chromatography developed by James \& Martin (1952) for shorter-chain fatty acids has been extended (James \& Martin, 1956a) to the methyl esters of higher fatty acids, and possesses the necessary high resolving power. When applied to sebum fatty acids it proved entirely suitable, and since less than $10 \mathrm{mg}$. of material is required for an analysis it can be applied to individual sebum samples.

\section{EXPERIMENTAL}

Sebum. A sample of sebum was collected from the forearms of six normal male subjects by the acetone method and was separated into free and combined fatty acids and non-saponifiable material by methods already described (MacKenna, Wheatley \& Wormall, 1950). The sample contained: free fatty acids $26.3 \%$, combined fatty acids $35.5 \%$ and unsaponifiable matter $33.8 \%$. The fatty acid fractions were esterified with methanol and $\mathrm{H}_{2} \mathrm{SO}_{4}$ and analysed on the gas-liquid chromatogram.

Gas-liquid partition chromatography. The columns used had as stationary phase the high-boiling lubricating oil described previously (James \& Martin, 1956a). Samples. were applied to the column with a micropipette (James \& Martin, 1956 b). Column temperatures were maintained at $197^{\circ}$ with boiling ethylene glycol. Bromination of the mixed esters was carried out as described by James \& Martin (1956a).

The measurement of peak areas was carried out by drawing lines through the points of inflexion in the sides of each peak. The area enclosed by the triangle so formed is about $4 \%$ less than the area of the peak. provided that the latter approximates closely to the shape of the Gaussian error curve (this is usually the case).

The response of the gas-density balance (Martin \& James, 1956) is proportional to the mol.wt. excess of the substance being detected (i.e. mol.wt. - mol.wt. of nitrogen, the carrier gas). The peak areas were corrected to those expected for a standard substance, in this case methyl palmitate, by the formula:

$$
\text { Peak area } \times \frac{M_{1}-28}{M_{2}-28} \times \frac{M_{2}}{M_{1}},
$$

where $M_{1}$ is the mol.wt. of the substance being detected and $M_{2}$ is the mol.wt. of methyl palmitate. The percentage of any component is then:

$$
\frac{\text { Corrected peak area }}{\text { Total corrected area of all peaks }} \times 100 \text {. }
$$

\section{RESULTS}

In Fig. 1, curve A, is shown the result obtained from the gas-liquid chromatograph with a sample of the mixed esters (4.8 mg.) of fatty acids occurring free in human sebum. A total of nineteen peaks in the range from methyl $n$-decanoate to methyl $n$ octadecanoate can be seen. The main components are methyl $n$-dodecanoate, $n$-tetradecanoate and $n$-hexadecanoate and a substance moving in front of methyl $n$-octadecanoate. The saturated acids present in the mixture, determined after conversion of the unsaturated acids into the virtually nonvolatile bromo acids by treatment of the mixture with bromine in ether, are shown in Fig. 1, curve $B$. Certain peaks have disappeared and others show a relative decrease, indicating an overlap of peaks due to saturated and unsaturated acids in curve $A$. Correlation of the two results suggests that at least twenty-nine components are present. 


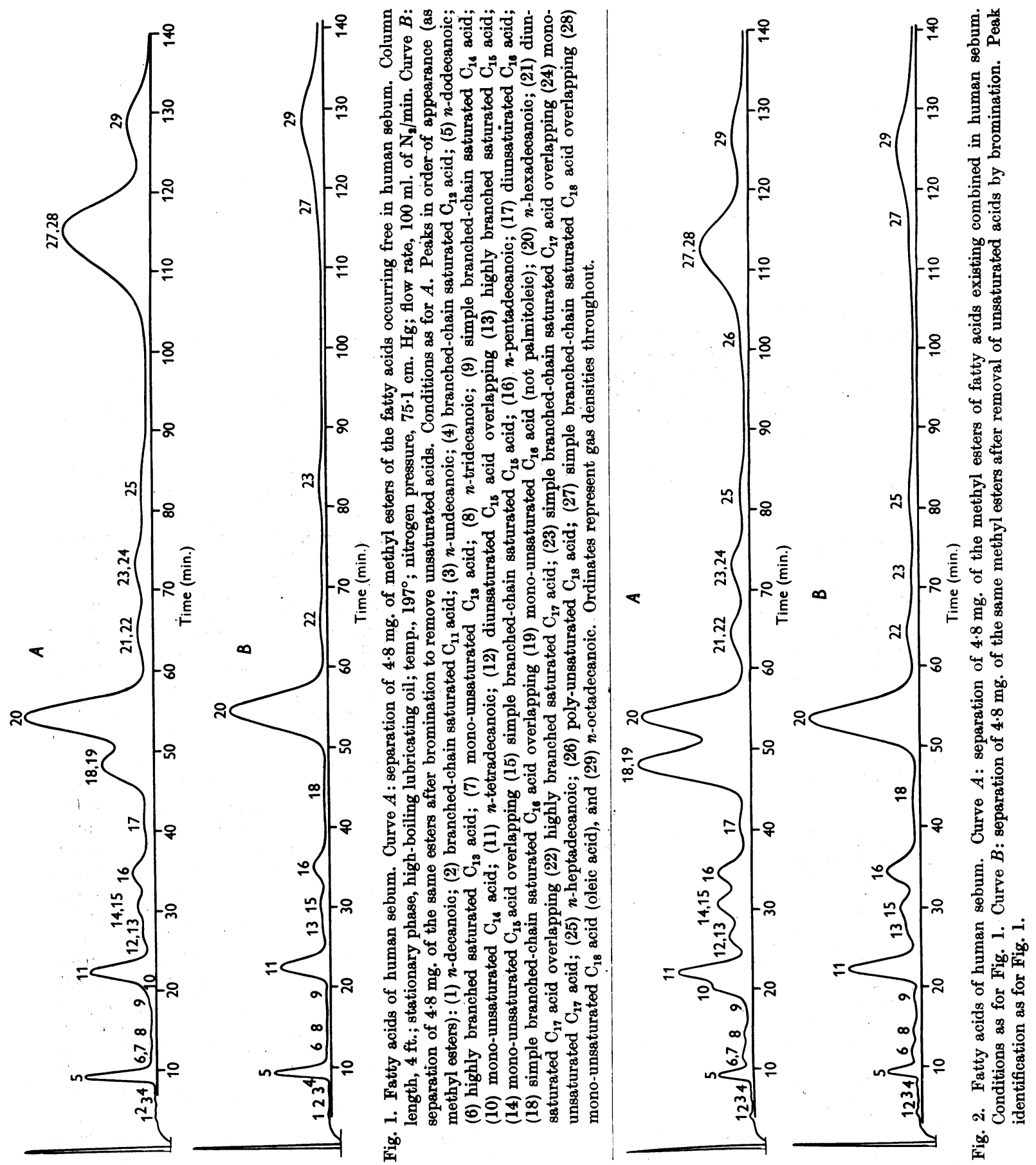




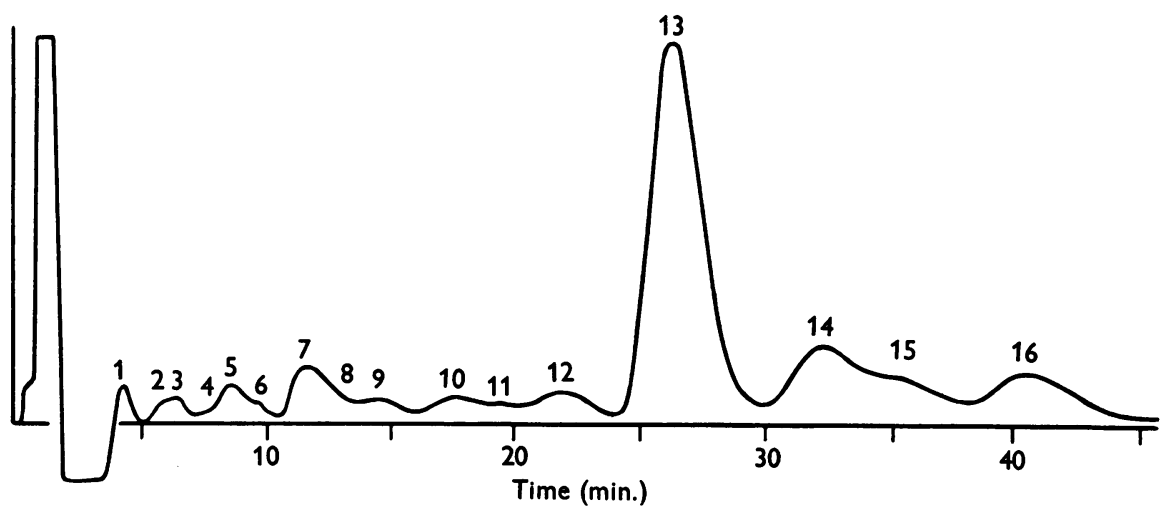

Fig. 3. Separation of methyl esters of free short-chain acids in human sebum. Total load 12 mg.; column conditions as Fig. 1, except that nitrogen pressure is $13 \mathrm{~cm}$. $\mathrm{Hg}$ and nitrogen flow rate $14.5 \mathrm{ml} . / \mathrm{min}$. Peak identification: (1) branched-chain $\mathrm{C}_{7}$ acid; (2) $n$-octanoic; (3) highly branched $\mathrm{C}_{9}$ acid; (4) $n$-nonanoic; (5) highly branched $\mathrm{C}_{10}$ acid; (6) simple branched-chain $\mathrm{C}_{10}$ acid; (7) $n$-decanoic; (8) highly branched $\mathrm{C}_{11}$ acid; (9) simple branched $\mathrm{C}_{11}$ acid; (10) $n$-undecanoic; (11) highly branched $\mathrm{C}_{12}$ acid; (12) simple branched $\mathrm{C}_{12}$ acid; (13) $n$-dodecanoic; (14) highly branched $\mathrm{C}_{13}$ acid; (15) simple branched $\mathrm{C}_{13}$ acid; (16) $n$-tridecanoic. Peak 13 corresponds with peak 5 in Fig. 1.

Table 1. Approximate analysis of the acids present in the free state in human sebum in the range $\mathrm{C}_{7}-\mathrm{C}_{18}$

\begin{tabular}{|c|c|}
\hline Acid & Percentage \\
\hline Saturated $n-\mathrm{C}_{7}$ & $\begin{array}{c}\text { Trace } \\
\text { (i.e. }<0.05 \%\end{array}$ \\
\hline Branched saturated $\mathrm{C}_{8}$ & Trace \\
\hline Saturated $n-\mathrm{C}_{8}$ & Trace \\
\hline Branched saturated $\mathrm{C}_{9}$ & Trace \\
\hline Saturated $n-\mathrm{C}_{9}$ & Trace \\
\hline Branched saturated $\mathrm{C}_{10}$ & Trace \\
\hline Saturated $n-\mathrm{C}_{10}$ & $0 \cdot 08$ \\
\hline Branched saturated $\mathrm{C}_{11}$ & Trace \\
\hline Saturated $n-\mathrm{C}_{11}$ & Trace \\
\hline Branched saturated $\mathrm{C}_{12}$ & Trace \\
\hline Saturated $n-\mathrm{C}_{12}$ & $3 \cdot 64$ \\
\hline Branched saturated $\mathrm{C}_{13}$ & $0 \cdot 25$ \\
\hline Saturated $n-\mathrm{C}_{13}$ & $0 \cdot 25$ \\
\hline Mono-unsaturated $\mathrm{C}_{14}$ & $0 \cdot 76$ \\
\hline Branched saturated $\mathrm{C}_{14}$ & $0 \cdot 32$ \\
\hline Saturated $n-\mathrm{C}_{14}$ & $6 \cdot 35$ \\
\hline Diunsaturated $\mathrm{C}_{15}$ & $0 \cdot 28$ \\
\hline Highly branched saturated $C_{15}$ & 0.54 \\
\hline Mono-unsaturated $\mathrm{C}_{15}$ & $0 \cdot 64$ \\
\hline Branched saturated $\mathrm{C}_{15}$ & $0 \cdot 67$ \\
\hline Saturated $n-\mathrm{C}_{15}$ & $2 \cdot 27$ \\
\hline Mono-unsaturated $\mathrm{C}_{16}$ & $9 \cdot 05$ \\
\hline Branched saturated $\mathrm{C}_{16}$ & $0 \cdot 29$ \\
\hline Saturated $n-\mathrm{C}_{16}$ & $24 \cdot 2$ \\
\hline Diunsaturated $\mathrm{C}_{17}$ & 0.69 \\
\hline Highly branched saturated $C_{17}$ & $1 \cdot 31$ \\
\hline Mono-unsaturated $\mathrm{C}_{17}$ & $1 \cdot 62$ \\
\hline Branched saturated $\widetilde{C}_{17}$ & $0 \cdot 73$ \\
\hline Saturated $n-\mathrm{C}_{17}$ & $1 \cdot 07$ \\
\hline Mono-unsaturated $\mathrm{C}_{18}$ & $35 \cdot 6$ \\
\hline Branched saturated $\mathrm{C}_{18}$ & $1 \cdot 8$ \\
\hline Saturated $n-\mathrm{C}_{18}$ & $8 \cdot 0$ \\
\hline
\end{tabular}

It was pointed out in an earlier publication (James \& Martin, 1956a) describing the application of the gas-liquid chromatogram to the long-chain fatty acids that the time of emergence of a peak can be used in structure identification. On this basis it is possible to give tentative identifications of the acids present in this natural mixture. These are as follows: peaks $1,3,5,8,11,16,20,25$ and 29 : the homologous series of saturated straight-chain acids of chain lengths from $\mathrm{C}_{10}$ to $\mathrm{C}_{18}$; peaks 2,6 , 13 and 22: a series of highly branched oddnumbered saturated acids of chain lengths $C_{11}$, $\mathrm{C}_{13}, \mathrm{C}_{15}$ and $\mathrm{C}_{17}$; peaks $7,12,17,21$ and 26 : unsaturated acids containing probably two double bonds and assignable to straight-chain acids of lengths $\mathrm{C}_{13}, \mathrm{C}_{15}, \mathrm{C}_{16}, \mathrm{C}_{17}$ and $\mathrm{C}_{18}$; peaks $9,15,18,23$ and 27: branched-chain saturated acids (the branch being probably a single methyl group) of lengths $C_{14}, C_{16}, C_{16}, C_{17}$ and $C_{18}$; peaks $10,14,19$, 24 and 28: mono-unsaturated acids, probably straight-chain, of lengths $\mathrm{C}_{14}, \mathrm{C}_{15}, \mathrm{C}_{16}, \mathrm{C}_{17}$ and $\mathrm{C}_{18}$.

The existence of these series is shown more clearly in Fig. 2, curves $A$ and $B$, which represent the result obtained from samples of the methyl esters of the combined fatty acids from human sebum. Although the relative proportions of the acids are different the general picture is the same as that obtained with the free fatty acids. Conclusive identification of the minor components must await their isolation and degradation. There is, however, no doubt that the $C_{16}$ unsaturated acid is not palmitoleic acid (hexadec-9-enoic acid), since its peak position is different from that due to palmitoleic acid. The $\mathrm{C}_{18}$ unsaturated acid lies in the position expected for methyl oleate. The existence of very small amounts of shorter-chain acids in sebum was demonstrated by using a higher load and running the chromatogram more slowly. Fig. 3 gives the result obtained under these conditions; at least sixteen components are present ranging in chain length from $\mathrm{C}_{7}$ to $\mathrm{C}_{13}$. The general pattern is 
very similar to that given by the higher acids. The closeness of the peaks renders identification by position more difficult, but it can be seen that in the range $C_{7}-C_{13}$ a number of simply branched and more highly branched acids exist, similar to those in the range $\mathrm{C}_{12}-\mathrm{C}_{18}$.

The straight-chain saturated acids present can be assigned to the following peaks: (4) $n$-nonanoic; (7) $n$-decanoic; (10) $n$-undecanoic; (13) $n$-dodecanoic; (16) $n$-tridecanoic.

The relative amounts of fatty acids obtained by measurement of peak areas are given in Table 1 for the acids occurring free in human sebum.

\section{DISCUSSION}

The results presented here extend and corroborate those of other workers. The higher resolution of the technique has shown not only the series of acids ranging from $n$-heptanoic to $n$-octadecanoic acid demonstrated by Weitkamp et al., but also two series of branched-chain acids. The first of these is assumed from its position on the chromatogram to consist of highly branched acids (though the possibility of cyclic structures should not be overlooked) and is restricted to the odd-number acids. The second series is considered to possess only a simple methyl branch and occurs with both odd and even numbers of carbon atoms. Both mono- and diunsaturated acids of a variety of chain lengths are present.

Chemical degradation of the $\mathbf{C}_{\mathbf{1 6}}$ mono-unsaturated acid by Weitkamp et al. showed it to be anomalous in that the double bond was located in the 6:7-position and not in the 9:10-position of the normally encountered palmitoleic acid. The chromatographic position of the $\mathbf{C}_{16}$ acid found here is not inconsistent with such an unsaturated acid. The presence of an unsaturated $\mathrm{C}_{18}$ acid in the position expected for methyl oleate agrees with the results of Weitkamp et al. (1947), Engman \& Kooyman (1934) and Ricketts et al. (1951), all of whom identified oleic acid in human sebum.

The relative amounts of acids present as estimated by measurement of peak areas (Table 1) vary only slightly from those reported by Weitkamp et al. (1947). In particular, only approximately $25 \%$ of the free $\mathbf{C}_{16}$ acids are unsaturated, as against the $50 \%$ previously reported; such a relationship exists only in the combined fatty acid fraction (Fig. 2, curve $A$ ). Smaller amounts of the short-chain acids than the figures given by Weit: kamp may be accounted for by losses due to solvent evaporation in the working up of the sebum samples.

No attempt has been made to extend the analysis to acids of chain length greater than $\mathrm{C}_{18}$, as such acids move very slowly under the conditions described and emerge at low concentration in broad bands. However, clear indications were found of the existence of branched-chain $\mathrm{C}_{19}$ acids, but no conclusions were drawn as to their structure. Extension of this analytical technique to the $\mathbf{C}_{\mathbf{1 9}}$, $\mathrm{C}_{20}$ and $\mathrm{C}_{22}$ acids will necessitate higher column temperatures.

\section{SUMMARY}

1. The fatty acids from human forearm sebum have been analysed by gas-liquid chromatography of their methyl esters.

2. Both odd- and even-numbered straight-chain fatty acids have been shown to be present as well as two types of branched-chain odd-numbered saturated fatty acids.

3. The principal unsaturated fatty acids contain 14,16 and 18 carbon atoms.

\section{REFERENCES}

Burtenshaw, J. M. L. (1942). J. Hyg., Camb., 42, 184.

Engman, M. F. \& Kooyman, D. J. (1934). Arch. Derm. Syph., N.Y., 29, 12.

James, A. T. \& Martin, A. J. P. (1952). Biochem. J. 50, 679.

James, A. T. \& Martin, A. J. P. (1956a). Biochem. J. 63, 144.

James, A. T. \& Martin, A. J. P. (1956b). J. appl. Chem. 6, 105.

MacKenna, R. M. B., Wheatley, V. R. \& Wormall, A. (1950). J. invest. Derm. 15, 33.

Martin A. J. P. \& James, A. T. (1956). Biochem. J. 63, 138.

Ricketts, C., Squire, J. R. \& Topley, E. (1951). Clin. Sci. 10, 89.

Rothman, S., Smiljanic, A. M., Shapiro, A. L. \& Weitkamp, A. (1947). J. invest. Derm. 8, 81.

Weitkamp, A. W., Smiljanic, A. M. \& Rothman, S. (1947). J. Amer. chem. Soc. 69, 1936.

Wheatley, V. R. (1954). Biochem. J. 58, 167. 